\title{
Executive function training in very preterm children: a randomized controlled trial
}

\author{
Carolien A. van Houdt ${ }^{1,2}$ (D) Aleid G. van Wassenaer-Leemhuis ${ }^{1}$. Jaap Oosterlaan ${ }^{3,4}$. \\ Marsh Königs $^{2}$. Corine Koopman-Esseboom ${ }^{5}$. A. R. Céleste Laarman ${ }^{6}$. Anton H. van Kaam ${ }^{1,6}$. \\ Cornelieke S. H. Aarnoudse-Moens $\mathbf{s}^{1,2,4,7}$
}

Received: 10 September 2019 / Accepted: 15 May 2020 / Published online: 26 May 2020

(c) The Author(s) 2020

\begin{abstract}
Objective of the current study was to assess whether game-formatted executive function (EF) training, is effective in improving attention, EF and academic performance in very preterm and/or extremely low birthweight children aged 8-12 years. A multi-center, double-blind, placebo- and waitlist controlled randomized trial (NTR5365) in two academic hospitals in The Netherlands was performed. Eighty-five very preterm children with parent-rated attention problems on the Child Behavior Checklist were randomized to one of three treatment conditions: EF training, placebo training or waitlist condition. EF or placebo training was completed at home (6 weeks, 25 sessions of 30-45 min each). At baseline, 2 weeks after training or being on the waitlist, and five months after first follow-up visit, children underwent assessments of primary outcomes (parent and teacher ratings of attention) and secondary outcomes (parent and teacher ratings of daily-life EF, computerized EF tasks and academic performance). Linear mixed model analyses were performed for all outcome measures. There were no significant differences in improvement over time on parent- and teacher ratings of attention, parent- and teacher ratings of daily-life EF, computerized EF tasks, and academic performance (arithmetic and reading) between the EF training, placebo training and waitlist condition. In conclusion, game-formatted EF training does not improve attention, EF or academic performance in very preterm children with parent-rated attention problems.
\end{abstract}

Keywords Intervention $\cdot$ Premature $\cdot$ Attention $\cdot$ Behavior $\cdot$ Arithmetic $\cdot$ Reading

\section{Introduction}

Electronic supplementary material The online version of this article (https://doi.org/10.1007/s00787-020-01561-0) contains supplementary material, which is available to authorized users.

Carolien A. van Houdt

c.a.vanhoudt@amsterdamumc.nl

1 Department of Neonatology, Emma Children's Hospital, Amsterdam UMC, University of Amsterdam, Meibergdreef 9, Amsterdam, The Netherlands

2 Emma Neuroscience Group, Emma Children's Hospital, Amsterdam UMC, University of Amsterdam, Meibergdreef 9, Amsterdam, The Netherlands

3 Department of Pediatrics, Amsterdam UMC, University of Amsterdam, Emma Neuroscience Group at Emma Children's Hospital, Amsterdam Reproduction and Development, Meibergdreef 9, Amsterdam, The Netherlands
In Western countries, $0.7-1.4 \%$ of all live born children are born very preterm (gestational age $(\mathrm{GA})<32$ weeks) [1]. Due to advances in medical care, survival rates have increased and approximately $65 \%$ of children born extremely

4 Clinical Neuropsychology Section, Vrije Universiteit Amsterdam, Van der Boechorststraat 7, Amsterdam, The Netherlands

5 Department of Neonatology, University Medical Center Utrecht, Heidelberglaan 100, Utrecht, The Netherlands

6 Department of Neonatology, Emma Children's Hospital, Amsterdam UMC, Vrije Universiteit Amsterdam, de Boelelaan 1117, Amsterdam, The Netherlands

7 Psychosocial Department, Emma Children's Hospital, Amsterdam UMC, University of Amsterdam, Meibergdreef 9, Amsterdam, The Netherlands 
preterm do not develop major disabilities [2]. However, more subtle problems in various domains are frequently encountered [3], which may have a significant negative impact on children's and parents' lives. One of the main and most persistent problems very preterm children encounter are problems in attentional functioning [4, 5]. Very preterm children have a two to four times higher risk of a diagnosis of Attention Deficit/Hyperactivity Disorder (ADHD) [6, 7], particularly the inattentive subtype [8], and an increased risk for an Autism Spectrum Disorder (ASD) diagnosis [8, 9]. Also in ASD, attentional problems are common [10] and several studies have shown high comorbidity rates of ADHD in children with ASD [11-15]. Although very preterm children's behavioral attentional symptoms may resemble those of children with ADHD or ASD for some aspects, such as inattentive symptoms, the biological underpinnings seem to differ. For example, a recent study, comparing adolescents with ADHD and adolescents born preterm on electrophysiological measures associated with attentional and inhibitory processing, found that preterm adolescents showed both impairments overlapping with those found in adolescents with ADHD and impairments unique for the preterm adolescents [16]. Moreover, the clinical presentation is also different. For example, the association between oppositional defiant disorder (ODD) and conduct disorder (CD) is much stronger in the general population than in children born extremely preterm [8]. Thus, interventions that were ineffective in children with ADHD may be effective in very preterm children with attention problems and vice versa.

Deficits in executive functions (EFs) are considered to play an important role in the complex neuropsychology of both ADHD and ASD [17-26]. Executive functioning is an umbrella term for a set of higher-order cognitive functions that allow for top-down, goal-directed behavior, with core functions including working memory, inhibition and cognitive flexibility [27]. Research has indicated that poor EFs are strongly associated with the attentional problems of very preterm children as well [28-30]. Both ASD and ADHD are neurodevelopmental disorders that affect key fronto-striatal and fronto-parietal circuits that are important for EFs [31], and very preterm birth has been shown to affect white matter network integrity and brain structures associated with EFs [32-39].

Computerized training interventions to improve EFs may therefore be one way to address the attentional problems very preterm children encounter. Cogmed Working Memory Training (CWMT) is widely used in children with Attention Deficit/Hyperactivity Disorder (ADHD) [40]. It has been coined as a promising computerized EF training for attentional problems [41], although more recent studies suggest that it might not be as effective as previously thought [42]. In very preterm children, a recent randomized controlled trial showed no effects of CWMT on any outcome measure, including attentional functioning [43]. However, CWMT solely trains working memory, while very preterm children show problems in inhibition and cognitive flexibility as well $[5,44,45]$. Recently, the BrainGame Brian training was developed [46], targeting not only working memory, but also inhibition and cognitive flexibility. BrainGame Brian training further expands upon the CWMT by adding game elements and using strong and immediate reinforcements to optimize children's motivational state. To date, effects of BrainGame Brian training have been assessed in three studies including children with clinically diagnosed ADHD and Autism Spectrum Disorder (ASD). These studies have consistently shown improvements in visuospatial working memory, although without consistent effects on other EFs or other untrained functions [47-49]. Previously, our group showed in a small sized non-randomized pilot study that BrainGame Brian training was a feasible intervention for very preterm children. Clinically significant benefits for visuospatial working memory were found [50].

The current study examined, using a double-blind, randomized controlled design including both a placebo- and a waitlist condition, whether game-formatted EF training (i.e., BrainGame Brian training) improves attentional functioning in very preterm $(\mathrm{GA}<30$ weeks) and/or extremely low birthweight children (birthweight $<1000 \mathrm{~g}$ ) aged 8 to 12 years. We also examined the effects of game-formatted EF training on secondary outcome measures. Because EF training is believed to improve attentional functioning through improving EFs, we examined whether gameformatted EF training indeed improved EFs. Last, as both attentional problems and EF deficits are strongly linked to worse academic performance in very preterm children [28, 29, 51-54], we also investigated whether game-formatted $\mathrm{EF}$ training improves academic performance, more specifically arithmetic and reading performance.

\section{Methods}

\section{Trial design and ethical considerations}

This multi-center, double-blind, placebo and waitlist controlled randomized trial was conducted in two academic hospitals in The Netherlands (Amsterdam University Medical Centers and University Medical Center Utrecht). Medical Ethical Committees in both centers approved the study protocol and execution of the study procedures was according to the Declaration of Helsinki. The trial was registered in the Dutch Trial Registry (NTR5365). CONSORT guidelines were followed. 


\section{Participants}

Parents of 7-12 year old children born very preterm and/or with extremely low birthweight (in short: very preterm children) who were admitted to the Neonatal Intensive Care Unit (NICU) in one of the two participating centers and who joined the neonatal follow-up program, were asked to complete the Dutch version of the Child Behavior Checklist (CBCL6-18 [55]). Children with parent-rated attention problems on the CBCL6-18 ( $T \geq 55$ on Attention Problems scale [56], as research has suggested this T-score is the optimal cut-off score for ADHD screening [56]) were eligible for this study as soon as they reached a minimum chronological age of 8 years. Exclusion criteria were estimated Intelligence Quotient (IQ) $<80$, motor problems too profound to allow use of a computer and no Dutch language use in the home situation.

\section{Randomization and blinding}

Children meeting inclusion criteria were randomly assigned to one of three treatment conditions: training-, placebo- or waitlist condition. Allocation to treatment conditions was stratified by age (below or above 10.5 years of age) and severity of attention problems (Attention Problems T-score below or above 65), with equal proportions of children allocated to each condition within each stratum. To ensure blinding to training- or placebo condition, parents were only informed about whether their child was randomized to either one of two training conditions or the waitlist condition and in case more children from the same family were included in the study, one of those was randomized and the other was allocated to the same condition. A random number generator was used to generate randomization lists. A researcher not otherwise involved in this study was responsible for randomization and handed the test assistant a sealed envelope with a note stating 'waitlist' or a login and password, which was opened by the child and parents after baseline assessment. All staff was blinded to training or placebo assignment, including the person involved in randomization. Test assistants that played the first training session with the child were deblinded because of differences in training tasks (see below) between training- and placebo condition and were not involved in follow-up assessments of these children. Parents, children and test administrators were aware of a child's allocation to the waitlist condition. Data were analyzed blinded to treatment allocations.

\section{Intervention}

\section{BrainGame Brian training}

Braingame Brian is a game-formatted computerized EF training, performed by the child at home. An elaborate description of the BrainGame Brian training can be found in Prins et al. [46]. BrainGame Brian is a game-world environment, in which three $\mathrm{EF}$ training tasks, one for each core $\mathrm{EF}$, are embedded. In each of 25 training sessions, children have to help the main character, Brian, to solve problems for other game-world characters. To do so, they play the three EF training tasks, which leads to the creation of an invention that solves the problem. For example, Brian meets a character that has a problem shearing his sheep. By playing the three EF training tasks, a sheep-shearing machine is invented, which solves the problem and remains visible in the game-world throughout the rest of the sessions to optimize motivational state and self-control of the children. In each session, children play the three training tasks twice. In total, 25 sessions are played, and the child and parents were instructed to play the BrainGame Brian training 4 times a week (approximately 30-45 min per session). After each session, session data were saved to a database, which was accessible for researchers to monitor fidelity to the training regimen. There was no additional support of researchers regarding motivation and/or feedback out of the computer game interface. For our randomized controlled trial, two versions of the BrainGame Brian EF training were used: the BrainGame Brian EF training, and a placebo version of the BrainGame Brian EF training. In the placebo version of the BrainGame Brian EF training, everything is identical to the BrainGame Brain EF training, except that the EF training tasks were replaced by placebo versions of these tasks. See below for the descriptions of the training tasks for both versions of the training.

\section{Training tasks in EF training condition}

In the working memory task, children are asked to repeat a sequence of dots on a $4 \times 4$ grid in a specific way (e.g., forwards, backwards). The instructions for this task change every five sessions to increase working memory demands. In the inhibition task, children are asked to press a button in a specific time window (target), but to refrain from pressing that button when a stop signal is presented. In the cognitive flexibility task, children are asked to sort objects according to one of two rules, with the sorting rule changing every three to five trials. After each block of all three training tasks, difficulty level of each task is automatically adjusted to the child's performance.

\section{Training tasks in placebo condition}

In the placebo versions of the EF training tasks, the elements actually training the EFs were removed, and difficulty level was set at the lowest difficulty level for all sessions regardless of the child's performance. In the placebo version of the working memory task, children are asked to repeat 
sequences in the same order as presented (which requires short-term memory, not working memory). This instruction remains the same throughout all training sessions. In the placebo version of the inhibition task, no stop signals are presented (thus children do not have to inhibit responses). In the placebo version of the cognitive flexibility task, the sorting rule never changes (thus no cognitive flexibility is required).

\section{Waitlist condition}

Children in the waitlist condition do not play the BrainGame Brian training and were instructed to perform the same activities in the waiting period as they normally do.

\section{Procedure}

After written informed consent was obtained from parents and, if applicable, children aged 12 years, and verbal informed consent was obtained from children below 12 years of age, participants completed a baseline neurocognitive assessment including measures of IQ, EF and academic functioning. Parents and teachers were asked to fill out questionnaires on children's attention and daily-life EF behavior. If children were randomized to the training- or placebo condition, a house visit was made to instruct children and parents and play the first session. In two follow-up visits, the neurocognitive assessment was repeated except for IQ, which was only administered at baseline. The first followup assessment (T1) was approximately two weeks after the last training session (approximately 2 months after baseline assessment for children in the waitlist condition) and the second follow-up assessment (T2) was approximately 5 months after the first follow-up assessment.

\section{Measures}

Primary outcome was parent- and teacher-rated attention as measured by the Strengths and Weaknesses of ADHD-symptoms and Normal Behavior (SWAN) questionnaire [57]. Secondary outcomes were (1) daily-life EF reported by parents and teachers as measured with the Behavior Rating Inventory of Executive Function (BRIEF) [58], (2) verbal working memory as measured using the Digit Span Backward subtest of the WISC-III-NL [59], (3) visuospatial working memory as measured using the Grid Task, backwards condition [60], (4) inhibition as measured with the Stop Signal Task [61], (5) cognitive flexibility as measured with the Multisensory Integration Test (MSIT) [62], (6) arithmetic as measured with the TempoTest Automatiseren (TTA) [63] and (7) Technical reading as measured with the Brus Een Minuut Test (B-EMT) [64]. Detailed descriptions of tasks and outcome measures can be found in Supplementary Material 1. Other secondary outcomes related to untrained functions were assessed as well, but were not included in the current paper on main outcome measures [65].

\section{IQ, demographic characteristics and medical characteristics of neonatal period}

IQ was estimated with a short-form of the Dutch Wechsler Intelligence Scale for Children, third edition (WISC-III-NL [59]), comprising the subtests Vocabulary and Block Design. Parents provided information on demographics. The Digit Span [59] and Grid Task [60] forwards conditions (repeating a sequence of spoken digits or dots on a grid in forwards order, respectively), were administered to provide maximal forwards span length. Neonatal medical data were obtained from medical records.

\section{Statistical analyses}

Sample size calculations determined that, to detect a medium-sized intervention effect (Cohen's $d=0.5$ ) on our primary outcome measure with a within-subject correlation of 0.295 [50] with a power of $80 \%$ and a significance level of $0.05,39$ children in each intervention arm were needed.

IBM SPSS Statistics version 24 was used for the statistical analyses [66]. Outliers were winsorized at three SDs [67]. Data were missing for less than 5\% of children, except for: the baseline assessments of the teacher SWAN (12.9\%), teacher BRIEF (14.1\%) and Stop Signal Task (9.4\%); the first follow-up assessments of the teacher SWAN (30.1\%), teacher BRIEF (30.1\%), Grid Task Backwards (6.8\%) and MSIT (9.6\%); the second follow-up assessments of the teacher SWAN (44.9\%), parent BRIEF (5.8\%), teacher BRIEF (40.6\%), Grid Task Backwards (17.4\%), Stop Signal Task (10.1\%) and MSIT (7.2\%). Missing data were not imputed.

Data were analyzed on intention-to-treat basis. To assess whether attrition from the study was selective, children that did and did not complete all assessments were compared on all demographic and neonatal medical characteristics with independent $t$ tests and chi-square tests.

To assess whether BrainGame Brian training improves attention, $\mathrm{EF}$ and academic performance, linear mixed model analyses were run for all primary and secondary outcome measures with a random intercept to account for dependency in the data due to family bonds, and fixed factors for treatment condition (training, placebo or waitlist condition), time (baseline, first follow-up and second follow-up assessment) and the interaction between the two. All available data (also of participants with missing data) were used in the linear mixed model analyses. Estimated marginal means were reported to aid interpretation of the results. 


\section{Results}

\section{Participants}

Participants' flow through the study process is depicted in Fig. 1. In short, 434 out of 1,019 parents returned the completed questionnaire. Main reasons not to return the questionnaire were no time or no interest. Of 234 children with elevated attention scores that were invited to participate, 97 agreed. Reasons to not participate were: already busy schedules for the child and/or family, or no interest. Two children withdrew from the study before randomization. Ten children were excluded due to estimated IQ $<80$. The remaining 85 children were randomized to a treatment condition (see Fig. 1). All children in the EF training and placebo training conditions that had at least one follow-up assessment, completed all 25 training sessions.

Randomization allocated 29 children to the training condition, 26 children to the placebo condition and 30 children to the waitlist condition. Twelve children withdrew from the study before the first follow-up visit and four withdrew before the second follow-up visit. Reasons for withdrawal were: not able to incorporate training sessions into busy schedule or child not wanting to complete training $(n=9)$, no time or willingness to schedule follow-up visit(s) at appropriate time-point(s) $(n=5)$ or severe illness discovered $(n=2)$. Of the included children $81 \%$ completed all assessments. Attrition analyses showed no differences in demographic and neonatal medical characteristics between children that did and did not complete all assessments (all $p$ values $>0.14$ ). As no data from nonparticipating children could be assessed, we could not perform attrition analyses regarding the representativeness of our sample. However, when compared to very preterm children included in previous cohort-studies of our research group, the GA and BW of the included children was similar (GA around 28 weeks and BW around $1000 \mathrm{~g}[3,68])$. Parental education level of our sample was high in $61 \%$ of children, compared to approximately $45 \%$ of the general Dutch population between 25-45 years of age being highly educated [69]. Assessments took place between October 2015 and September 2018. Demographics and neonatal medical characteristics are presented in Table 1.

\section{Primary and secondary outcome measures}

There were no significant differences over time between the three treatment conditions for both parent and teacher SWAN questionnaires, indicating no beneficial effects of

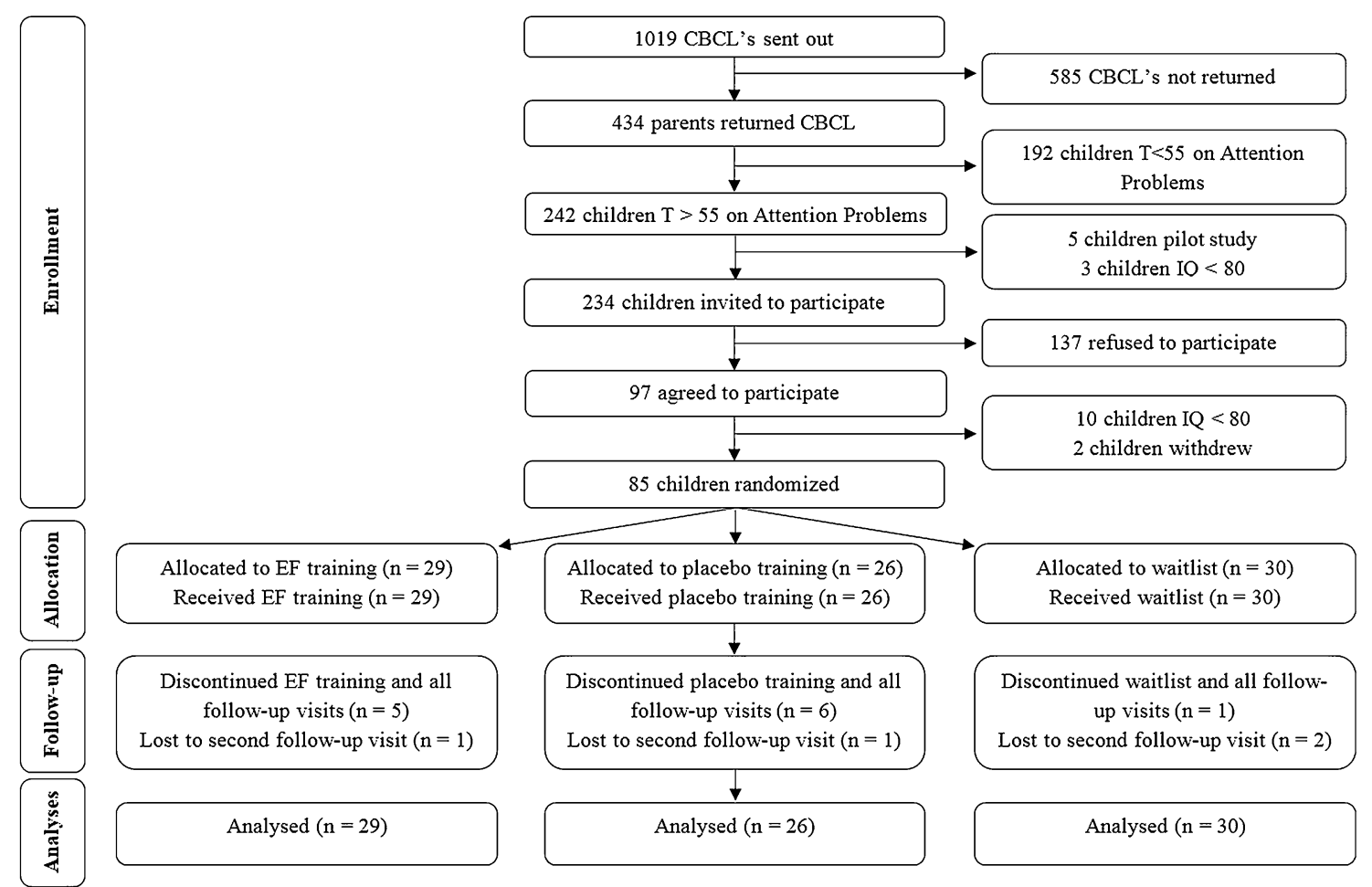

Fig. 1 CONSORT flow diagram. $C B C L$ child behavior checklist, $I Q$ intelligence quotient, $E F$ Executive function. Re-used from Van Houdt et al. [65]. Copyright 2019 by van Houdt, Aarnoudse-Moens, van Wassenaer-Leemhuis, Laarman, Koopman-Esseboom, van Kaam and Oosterlaan 
Table 1 Demographic and neonatal medical characteristics for the three treatment groups

\begin{tabular}{llll}
\hline Measure & BGB-Training $(n=29)$ & BGB-Placebo $(n=26)$ & Waitlist $(n=30)$ \\
\hline Demographic characteristics: & & & \\
GA (M, SD) & $28.2(1.3)$ & $28.0(1.0)$ & $27.8(1.4)$ \\
BW (gram; M, SD) & $1026(256)$ & $1039(179)$ & $1049(267)$ \\
Age (years; M, SD) & $10.2(1.2)$ & $10.2(1.3)$ & $10.3(1.1)$ \\
IQ (M, SD) & $99.0(13.6)$ & $96.4(11.7)$ & $100.8(11.1)$ \\
CBCL attention $T$ score (M, SD) & $62.8(6.9)$ & $64.0(7.6)$ & $64.4(7.0)$ \\
Digit span forwards span length & $5.1(0.9)$ & $5.1(1.1)$ & $5.1(0.8)$ \\
Grid task forwards span length & $4.2(1.2)$ & $4.0(1.3)$ & $4.6(1.2)$ \\
Boys $(n, \%)$ & $13(45 \%)$ & $16(62 \%)$ & $20(67 \%)$ \\
Parental education level $(n /$ total $n)$ & & & $1 / 28$ \\
Low & $6 / 29$ & $4 / 25$ & $11 / 28$ \\
Middle & $3 / 29$ & $5 / 25$ & $16 / 28$ \\
High & $20 / 29$ & $16 / 25$ & \\
Neonatal medical characteristics & & & $4(13 \%)$ \\
SGA $(n, \%)$ & $8(28 \%)$ & $4(15 \%)$ & $23(77 \%)$ \\
Ventilator support $(n, \%)$ & $20(69 \%)$ & $17(65 \%)$ & $5(17 \%)$ \\
BPD at 36 weeks PMA $(n, \%)$ & $6(21 \%)$ & $4(15 \%)$ & $8(27 \%)$ \\
IVH I or II & $9(31 \%)$ & $6(23 \%)$ & $1(3 \%)$ \\
IVH III or IV & $0(0 \%)$ & $2(8 \%)$ & $0(0 \%)$ \\
PVL I & $1(3 \%)$ & $2(8 \%)$ & $0(0 \%)$ \\
PVL II, III or IV & $0(0 \%)$ & $0(0 \%)$ & $13(43 \%)$ \\
Open ductus botalli treated & $3(10 \%)$ & $12(46 \%)$ & $20(67 \%)$ \\
Sepsis & $17(59 \%)$ & $16(62 \%)$ & \\
\hline
\end{tabular}

$B G B$ BrainGame Brian, $G A$ gestational age, $B W$ birth weight, $I Q$ intelligence quotient, $C B C L$ child behavior check list, $S G A$ small for gestational age, $B P D$ broncho pulmonary dysplasia, $P M A$ post menstrual age, $I V H$ intra ventricular hemorrhage, $P V L$ peri ventricular leukomalacia, $M$ mean, SD standard deviation, $n$ number the BrainGame Brian training as compared to the placebo or waitlist condition.

There were also no significant differences over time between the three treatment conditions for any of the EF measures, indicating no beneficial effects of the BrainGame Brian training as compared to the placebo or waitlist condition. Last, there were no significant differences over time between the three treatment conditions for both the TTA and B-EMT, indicating no beneficial effects of the BrainGame Brian training as compared to the placebo or waitlist condition.

There were significant main effects of time for teacher BRIEF Working Memory and Total Score, Grid Task Backwards, Stop Signal Task, TTA and B-EMT, all indicating better performance over time. There were significant main effects of group for the Grid Task Backwards and MSIT, both indicating poorer performance in the placebo training group than in the BrainGame Brian training group and the waitlist group, with no difference in performance between the latter two (see Tables 2 and 3).

\section{Discussion}

The present study investigated whether game-formatted EF training improves attentional functioning in children born very preterm and/or with extremely low birthweight (in short: very preterm) with parent-rated attention problems. Additional outcomes included computerized EF tasks, parent- and teacher reported daily-life EF and academic performance. Results of our double-blind RCT provided no evidence for beneficial effects on any of the outcome measures assessed.

In children with ADHD, positive effects of both BrainGame Brian training and CWMT on working memory performance have been found [48, 70-72]. Because behavioral symptoms of inattention in children born very preterm resemble those of children with ADHD, we expected positive effects in children born very preterm. However, results of our study indicated no positive effects of the BrainGame Brian training in children born 
Table 2 Baseline and follow-up data on the SWAN for the three intervention groups

\begin{tabular}{|c|c|c|c|c|c|c|}
\hline Outcome measure & $T 0$ & $T 1$ & $T 2$ & $\begin{array}{l}p \text { value effect of } \\
\text { intervention condi- } \\
\text { tion }\end{array}$ & $\begin{array}{l}p \text { value } \\
\text { effect of } \\
\text { time }\end{array}$ & $\begin{array}{l}p \text { value interaction effect of } \\
\text { intervention condition } \mathrm{x} \text { time }\end{array}$ \\
\hline \multicolumn{7}{|l|}{ SWAN parent } \\
\hline Attention deficit (M, SE) & & & & .17 & .18 & .91 \\
\hline BGB-Training & $40.1(1.4)$ & $39.9(1.5)$ & $38.9(1.5)$ & & & \\
\hline BGB-Placebo & $42.2(1.4)$ & $43.1(1.5)$ & $42.0(1.6)$ & & & \\
\hline Waitlist & $42.6(1.3)$ & $43.8(1.4)$ & $42.0(1.4)$ & & & \\
\hline Hyperactivity/impulsivity (M, SE) & & & & .69 & .12 & .69 \\
\hline BGB-Training & $38.1(1.5)$ & $38.7(1.6)$ & $36.6(1.6)$ & & & \\
\hline BGB-Placebo & $40.6(1.6)$ & $38.9(1.7)$ & $38.7(1.7)$ & & & \\
\hline Waitlist & $39.7(1.4)$ & $39.2(1.5)$ & $38.8(1.5)$ & & & \\
\hline Total score (M, SE) & & & & .29 & .06 & .98 \\
\hline BGB-Training & $78.4(2.5)$ & $79.3(2.6)$ & $75.5(2.6)$ & & & \\
\hline BGB-Placebo & $82.9(2.5)$ & $82.9(2.7)$ & $80.7(2.8)$ & & & \\
\hline Waitlist & $82.3(2.3)$ & $83.0(2.4)$ & $80.7(2.4)$ & & & \\
\hline \multicolumn{7}{|l|}{ SWAN teacher } \\
\hline Attention deficit (M, SE) & & & & .17 & .05 & .58 \\
\hline BGB-Training & $37.7(1.6)$ & $37.7(1.6)$ & $37.0(1.8)$ & & & \\
\hline BGB-Placebo & $40.6(1.7)$ & $40.6(1.9)$ & $39.0(2.1)$ & & & \\
\hline Waitlist & $42.3(1.5)$ & $42.8(1.6)$ & $39.0(1.7)$ & & & \\
\hline Hyperactivity/impulsivity (M, SE) & & & & .35 & .81 & .41 \\
\hline BGB-Training & $34.1(1.9)$ & $32.2(2.0)$ & $33.9(2.2)$ & & & \\
\hline BGB-Placebo & $36.4(2.0)$ & $34.6(2.4)$ & $36.3(2.7)$ & & & \\
\hline Waitlist & $36.7(1.8)$ & $38.3(2.0)$ & $35.4(2.1)$ & & & \\
\hline Total score (M, SE) & & & & .18 & .42 & .38 \\
\hline BGB-Training & $71.8(3.0)$ & $70.0(3.2)$ & $70.9(3.5)$ & & & \\
\hline BGB-Placebo & $76.9(3.2)$ & $75.2(3.7)$ & $75.5(4.2)$ & & & \\
\hline Waitlist & $78.9(2.9)$ & $81.1(3.1)$ & $74.3(3.3)$ & & & \\
\hline
\end{tabular}

SWAN strengths and weaknesses of ADHD-symptoms and normal behavior, $B G B$ BrainGame Brian, $M$ mean, $S E$ standard error, TOTime-point 0 , i.e. baseline, $T 1$ time-point 1, i.e. first follow-up visit, $T 2$ time-point 2, i.e. second follow-up visit. See Fig. 1 for number of participants in each group at each time-point

very preterm. Results of our study are in line with a randomized controlled trial investigating effects of CWMT in very preterm children, with no positive effects of CWMT on attentional functioning, working memory performance and academic performance [43]. Also, we recently analyzed our other secondary outcome measures including behavioral and emotional functioning and self-perceived competence [65]. None of these untrained functions were improved by BrainGame Brian training either. Our results are also in line with previous meta-analyses investigating the effect of CWMT on far transfer measures in children with ADHD [41, 42, 73, 74]. Despite the behavioral parallels between ADHD and symptoms of inattention in children born very preterm, the neurobiological underpinnings of these symptoms may actually be different. A recent study, for instance, using electroencephalography (EEG) measures associated with attentional and inhibitory processing, demonstrated that adolescents born preterm show unique patterns of aberrant neural activity as compared to adolescents with ADHD, suggestive of more generalized impairments in adolescents born preterm as compared to adolescents with ADHD [16]. This implies that interventions that are not effective in children with ADHD may be effective in very preterm children with attention problems and vice versa, and examining intervention effects in both populations instead of in one population and then generalizing the results to the other population, is extremely important.

An important prerequisite for improvement of EF and/ or attentional functioning following EF training is plasticity of white matter networks and basal ganglia. In very preterm children, compromised white matter tract integrity and white matter abnormalities are associated with both EF- and attention problems [75-77]. Moreover, damage to the basal ganglia is also associated with attention problems [78] and is frequently observed in children born 
Table 3 Baseline and follow-up data on EF and academic performance for the three intervention groups

\begin{tabular}{|c|c|c|c|c|c|c|}
\hline Outcome measure & $T 0$ & $T 1$ & $T 2$ & $\begin{array}{l}p \text { value effect of } \\
\text { intervention condi- } \\
\text { tion }\end{array}$ & $\begin{array}{l}p \text { value } \\
\text { effect of } \\
\text { time }\end{array}$ & $\begin{array}{l}p \text { value interaction effect of } \\
\text { intervention condition } \mathrm{x} \text { time }\end{array}$ \\
\hline $\begin{array}{l}\text { BRIEF parent working memory } \\
(\mathrm{M}, \mathrm{SE})\end{array}$ & & & & .33 & .06 & .61 \\
\hline BGB-Training & $57.45(1.68)$ & $56.09(1.74)$ & $54.12(1.83)$ & & & \\
\hline BGB-Placebo & $56.56(1.70)$ & $57.47(1.87)$ & $54.79(1.90)$ & & & \\
\hline Waitlist & $58.75(1.58)$ & $59.13(1.60)$ & $58.28(1.62)$ & & & \\
\hline BRIEF parent inhibit (M, SE) & & & & .20 & .27 & .74 \\
\hline BGB-Training & $51.23(2.05)$ & $49.70(2.12)$ & $48.65(2.20)$ & & & \\
\hline BGB-Placebo & $54.98(2.07)$ & $52.93(2.24)$ & $53.94(2.27)$ & & & \\
\hline Waitlist & $54.27(1.92)$ & $54.57(1.95)$ & $53.55(1.96)$ & & & \\
\hline $\begin{array}{l}\text { BRIEF parent cognitive flexibility } \\
(\mathrm{M}, \mathrm{SE})\end{array}$ & & & & .57 & .27 & .64 \\
\hline BGB-Training & $52.06(2.00)$ & $50.26(2.08)$ & $50.30(2.17)$ & & & \\
\hline BGB-Placebo & $48.77(2.02)$ & $47.45(2.22)$ & $48.55(2.25)$ & & & \\
\hline Waitlist & $51.34(1.87)$ & $51.08(1.91)$ & $48.56(1.92)$ & & & \\
\hline BRIEF parent total $(\mathrm{M}, \mathrm{SE})$ & & & & .33 & .54 & .53 \\
\hline BGB-Training & $52.41(1.88)$ & $51.57(1.95)$ & $49.75(2.03)$ & & & \\
\hline BGB-Placebo & $52.75(1.90)$ & $53.48(2.07)$ & $53.99(2.10)$ & & & \\
\hline Waitlist & $54.74(1.77)$ & $55.57(1.79)$ & $53.95(1.81)$ & & & \\
\hline $\begin{array}{l}\text { BRIEF teacher working memory } \\
(\mathrm{M}, \mathrm{SE})\end{array}$ & & & & .63 & $.001 *$ & .96 \\
\hline BGB-Training & $58.40(3.03)$ & $58.62(3.20)$ & $53.70(3.27)$ & & & \\
\hline BGB-Placebo & $61.93(3.30)$ & $63.79(3.55)$ & $57.18(3.94)$ & & & \\
\hline Waitlist & $60.00(2.92)$ & $59.37(3.05)$ & $54.42(3.13)$ & & & \\
\hline BRIEF teacher inhibit (M, SE) & & & & .59 & .67 & .39 \\
\hline BGB-Training & $49.43(1.94)$ & $48.79(2.14)$ & $51.02(2.21)$ & & & \\
\hline BGB-Placebo & $53.08(2.15)$ & $52.00(2.43)$ & $51.03(2.85)$ & & & \\
\hline Waitlist & $52.92(1.88)$ & $52.95(2.03)$ & $50.07(2.12)$ & & & \\
\hline $\begin{array}{l}\text { BRIEF teacher cognitive flexibil- } \\
\text { ity (M, SE) }\end{array}$ & & & & .83 & .67 & .96 \\
\hline BGB-Training & $55.29(2.77)$ & $54.69(3.08)$ & $53.73(3.19)$ & & & \\
\hline BGB-Placebo & $52.66(3.08)$ & $53.19(3.49)$ & $52.39(4.12)$ & & & \\
\hline Waitlist & $52.51(2.69)$ & $54.38(2.91)$ & $50.90(3.05)$ & & & \\
\hline BRIEF teacher total (M, SE) & & & & .59 & $.03 *$ & .27 \\
\hline BGB-Training & $52.60(2.25)$ & $53.15(2.40)$ & $51.72(2.45)$ & & & \\
\hline BGB-Placebo & $54.84(2.46)$ & $57.95(2.67)$ & $54.52(3.00)$ & & & \\
\hline Waitlist & $55.81(2.17)$ & $55.60(2.28)$ & $50.65(2.35)$ & & & \\
\hline Digit span backwards (M, SE) & & & & .67 & .91 & .94 \\
\hline BGB-Training & $16.19(1.75)$ & $16.77(1.88)$ & $17.77(1.91)$ & & & \\
\hline BGB-Placebo & $17.67(1.81)$ & $16.50(2.03)$ & $17.04(2.12)$ & & & \\
\hline Waitlist & $15.79(1.68)$ & $15.31(1.71)$ & $15.31(1.78)$ & & & \\
\hline Grid task backwards (M, SE) & & & & $.02 *$ & $.02 *$ & .33 \\
\hline BGB-Training & $35.30(5.40)$ & $50.88(6.26)$ & $56.76(6.94)$ & & & \\
\hline BGB-Placebo & $27.17(5.54)$ & $30.98(6.39)$ & $34.57(6.96)$ & & & \\
\hline Waitlist & $38.39(5.15)$ & $48.24(5.23)$ & $40.10(5.60)$ & & & \\
\hline \multicolumn{7}{|l|}{ Stop task } \\
\hline SSRT (M, SE) & & & & .99 & $.002 *$ & .49 \\
\hline BGB-Training & $323.4(30.8)$ & $293.3(31.9)$ & $288.9(32.2)$ & & & \\
\hline BGB-Placebo & $312.4(31.4)$ & $302.0(34.6)$ & $270.3(33.5)$ & & & \\
\hline Waitlist & $310.3(30.0)$ & $316.3(29.6)$ & $263.6(30.2)$ & & & \\
\hline
\end{tabular}


Table 3 (continued)

\begin{tabular}{|c|c|c|c|c|c|c|}
\hline Outcome measure & $T 0$ & $T 1$ & $T 2$ & $\begin{array}{l}p \text { value effect of } \\
\text { intervention condi- } \\
\text { tion }\end{array}$ & $\begin{array}{l}p \text { value } \\
\text { effect of } \\
\text { time }\end{array}$ & $\begin{array}{l}p \text { value interaction effect of } \\
\text { intervention condition } \mathrm{x} \text { time }\end{array}$ \\
\hline \# errors (M, SE) & & & & .61 & $.01 *$ & .32 \\
\hline BGB-Training & $5.21(1.26)$ & $3.08(1.43)$ & $3.93(1.40)$ & & & \\
\hline BGB-Placebo & $6.06(1.30)$ & $3.41(1.69)$ & $3.41(1.50)$ & & & \\
\hline Waitlist & $6.66(1.21)$ & $6.30(1.19)$ & $3.35(1.27)$ & & & \\
\hline $\begin{array}{l}\text { MSIT shifting accuracy loss (M, } \\
\text { SE) }\end{array}$ & & & & $.002 *$ & .25 & .35 \\
\hline BGB-Training & $3.4 \%(2.1 \%)$ & $3.2 \%(2.3 \%)$ & $3.1 \%(2.4 \%)$ & & & \\
\hline BGB-Placebo & $14.4 \%(2.2 \%)$ & $12.9 \%(2.7 \%)$ & $7.4 \%(2.5 \%)$ & & & \\
\hline Waitlist & $3.9 \%(2.0 \%)$ & $5.5 \%(2.0 \%)$ & $4.1 \%(2.1 \%)$ & & & \\
\hline TTA (M, SE) & & & & .95 & $<.001 *$ & .95 \\
\hline BGB-Training & $90.3(9.5)$ & $97.6(9.6)$ & $101.3(9.7)$ & & & \\
\hline BGB-Placebo & $93.0(9.7)$ & $103.1(10.0)$ & $105.9(10.0)$ & & & \\
\hline Waitlist & $89.8(9.0)$ & $97.7(9.0)$ & $104.7(9.1)$ & & & \\
\hline B-EMT (M, SE) & & & & .99 & $.001 *$ & .99 \\
\hline BGB-Training & $59.6(3.7)$ & $61.5(3.8)$ & $64.5(3.8)$ & & & \\
\hline BGB-Placebo & $60.8(3.7)$ & $61.3(3.9)$ & $65.7(4.0)$ & & & \\
\hline Waitlist & $60.1(3.5)$ & $61.7(3.5)$ & $65.3(3.5)$ & & & \\
\hline
\end{tabular}

$B G B$ BrainGame Brian, BRIEF Behavior Rating Inventory of Executive Function, SSRT stop signal reaction time, MSIT multisensory integration task, $B$-EMTBrus-Een minuut test, $T T A$ tempo test automatiseren, $M$ mean, $S E$ standard error, $T 0$ time-point 0 , i.e. baseline, $T 1$ time-point 1 , i.e. first follow-up visit, $T 2$ time-point 2, i.e. second follow-up visit. See Fig. 1 for number of participants in each group at each time-point

*Significant at alpha $<.05$

very preterm [79]. Research has shown that EF training can induce neural changes in brain areas associated with attention in very preterm children [80] and that exercise intervention can induce improvements in white matter integrity in children [81]. It thus seems that the very preterm brain does show the plasticity required for improvement of EF and/or attentional functioning. Possibly, the intensity and duration of the BrainGame Brian training and CWMT in its current forms are not sufficient to induce changes in EF in very preterm children. This is supported by the fact that all children in the EF training condition that had at least one follow-up assessment (24 out of 29, 83\%) completed all training sessions, thereby ruling out that not finding any positive results was due to infidelity to the training regimen. Because we did not include brain measures, we cannot rule out that the BrainGame Brian training did induce changes in the brain that did not subsequently lead to changes in attention, behavior or academic performance. However, a recent randomized controlled trial on CWMT in extremely preterm children concluded that brain changes (both structural and functional) generally did not differ between CWMT and placebo conditions [82]. Thus, to induce changes in brain measures and attention, behavior or academic performance, it is likely that more intense and longer training is required. Furthermore, children's motivation could play a role in the (absence of) training effects. In our study, we did not measure this. However, in a previous pilot study of our group, it was reported that "the majority of parents were positive about BrainGame Brian, in that it is enjoyable and motivating" [50].

Given the growing evidence of ineffectiveness of EF training, alternative interventions should be investigated. One alternative that might come to mind is targeting lowerorder cognitive skills with cognitive training, instead of EF (which are higher-order cognitive skills). However, the placebo training condition may be considered as lower-order cognitive training: the child does not train EFs, but still has to remain alert and pay attention to the task in order to perform it correctly. If lower-order cognitive training would be effective, we would therefore expect to find larger improvements following placebo training than following $\mathrm{EF}$ training or waitlist condition, which was not the case. A recent meta-analysis on EF training in very preterm children at preschool-age specifically (3-6 years of age) concluded that EF training does have positive results in this population, especially when it is non-computerized and in a group setting [83]. Therefore, we suggest that focus should be directed towards training programs that target younger children, combine exercise and tasks demanding EFs and take place in group settings.

A limitation of the current study is not meeting the required numbers according to our power calculations. However, 
differences between groups over time were small and not clinically meaningful. Another limitation is that the current study included children with attention problems, and not necessarily children with EF problems. The rationale was that previous studies have shown that EF impairments play an important underlying role in the attention problems observed in very preterm children [28-30]. Last, despite substantial efforts, a large number of teacher questionnaires was missing, especially at the second follow-up visit. However, additional analyses revealed that there were no significant differences in our teacher primary outcome measure at baseline between children with and without the teacher primary outcome measure at second follow-up visit, nor were there any significant differences in demographics between these children. Strengths of the present study are incorporation of both a placebo- and a waitlist control condition, intention-to-treat analyses, comprehensive assessment of a broad range of outcomes using multi-dimensional techniques (questionnaires and performance-based tests) and informants (parent and teacher questionnaires), and assessment of both direct effects and effects five months after the intervention ended.

\section{Conclusion}

Game-formatted EF training is not effective in improving attention, EF or academic functioning in very preterm children with attention problems. Future research may investigate whether alterations to $\mathrm{EF}$ training would make such training effective in very preterm children. For example, effectiveness may be enhanced with more ecologically valid and intrinsically rewarding training tasks and/or with longer and more intensive training [84]. Parallel to this, research should also look beyond game-formatted training for interventions to improve EF and associated areas of functioning.

Funding Grants from the Stichting Kinderpostzegels Nederland, Cornelia Stichting, Stichting Zabawas and Stichting Elise Mathilde Fonds.

\section{Compliance with ethical standards}

Conflict of interest On behalf of all authors, the corresponding author states that there is no conflict of interest.

Ethical standards statement This study has been approved by the appropriate Medical Ethical Committees and has been performed in accordance with the ethical standards laid down in the 1964 Declaration of Helsinki and its later amendments. Parents of all children and, if applicable, children aged 12 years gave informed consent prior to inclusion in the study.

Open Access This article is licensed under a Creative Commons Attribution 4.0 International License, which permits use, sharing, adaptation, distribution and reproduction in any medium or format, as long as you give appropriate credit to the original author(s) and the source, provide a link to the Creative Commons licence, and indicate if changes were made. The images or other third party material in this article are included in the article's Creative Commons licence, unless indicated otherwise in a credit line to the material. If material is not included in the article's Creative Commons licence and your intended use is not permitted by statutory regulation or exceeds the permitted use, you will need to obtain permission directly from the copyright holder. To view a copy of this licence, visit http://creativecommons.org/licenses/by/4.0/.

\section{References}

1. Delnord M, Hindori-Mohangoo AD, Smith LK, Szamotulska K, Richards JL, Deb-Rinker P, Rouleau J, Velebil P, Zile I, Sakkeus L (2017) Variations in very preterm birth rates in 30 high-income countries: are valid international comparisons possible using routine data? BJOG Int J Obstet Gynaecol 124 (5):785-794

2. Lorenz JM (2011) Survival and long-term neurodevelopmental outcome of the extremely preterm infant. A systematic review. Saudi Med J 32(9):885-894

3. Potharst ES, van Wassenaer AG, Houtzager BA, van Hus JW, Last BF, Kok JH (2011) High incidence of multi-domain disabilities in very preterm children at five years of age. J Pediatr 159(1):79-85. https://doi.org/10.1016/j.jpeds.2010.12.055

4. Shum D, Neulinger K, O'Callaghan M, Mohay H (2008) Attentional problems in children born very preterm or with extremely low birth weight at 7-9 years. Arch Clin Neuropsychol 23(1):103112. https://doi.org/10.1016/j.acn.2007.08.006

5. Aarnoudse-Moens CSH, Weisglas-Kuperus N, van Goudoever JB, Oosterlaan J (2009) Meta-analysis of neurobehavioral outcomes in very preterm and/or very low birth weight children. Pediatrics 124(2):717-728. https://doi.org/10.1542/peds.2008-2816

6. Bhutta AT, Cleves MA, Casey PH, Cradock MM, Anand KJ (2002) Cognitive and behavioral outcomes of school-aged children who were born preterm: a meta-analysis. JAMA 288(6):728-737

7. Allotey J, Zamora J, Cheong-See F, Kalidindi M, Arroyo-Manzano D, Asztalos E, van der Post J, Mol BW, Moore D, Birtles D, Khan KS, Thangaratinam S (2017) Cognitive, motor, behavioural and academic performances of children born preterm: a metaanalysis and systematic review involving 64061 children. BJOG Int J Obstet Gynaecol. https://doi.org/10.1111/1471-0528.14832

8. Johnson S, Hollis C, Kochhar P, Hennessy E, Wolke D, Marlow N (2010) Psychiatric disorders in extremely preterm children: longitudinal finding at age 11 years in the EPICure study. J Am Acad Child Adolesc Psychiatry 49(5):453-463.e451

9. Johnson S, Hollis C, Kochhar P, Hennessy E, Wolke D, Marlow N (2010) Autism spectrum disorders in extremely preterm children. J Pediatr 156(4):525-531.e522. https://doi.org/10.1016/j. jpeds.2009.10.041

10. Sturm H, Fernell E, Gillberg C (2004) Autism spectrum disorders in children with normal intellectual levels: associated impairments and subgroups. Dev Med Child Neurol 46(7):444-447

11. Gadow KD, DeVincent CJ, Pomeroy J (2006) ADHD symptom subtypes in children with pervasive developmental disorder. J Autism Dev Disord 36(2):271-283. https://doi.org/10.1007/s1080 3-005-0060-3

12. Holtmann M, Bolte S, Poustka F (2007) Attention deficit hyperactivity disorder symptoms in pervasive developmental disorders: association with autistic behavior domains and coexisting psychopathology. Psychopathology 40(3):172-177. https://doi. org/10.1159/000100007

13. Lee DO, Ousley OY (2006) Attention-deficit hyperactivity disorder symptoms in a clinic sample of children and adolescents with pervasive developmental disorders. J Child Adolesc Psychopharmacol 16(6):737-746. https://doi.org/10.1089/cap.2006.16.737 
14. Simonoff E, Pickles A, Charman T, Chandler S, Loucas T, Baird G (2008) Psychiatric disorders in children with autism spectrum disorders: prevalence, comorbidity, and associated factors in a population-derived sample. J Am Acad Child Adolesc Psychiatry 47(8):921-929. https://doi.org/10.1097/CHI.0b013e318179964f

15. Yoshida Y, Uchiyama T (2004) The clinical necessity for assessing attention deficit/hyperactivity disorder (AD/HD) symptoms in children with high-functioning pervasive developmental disorder (PDD). Eur Child Adolesc Psychiatry 13(5):307-314. https://doi. org/10.1007/s00787-004-0391-1

16. Rommel AS, James SN, McLoughlin G, Brandeis D, Banaschewski T, Asherson P, Kuntsi J (2017) Association of preterm birth with attention-deficit/hyperactivity disorder-like and wider-ranging neurophysiological impairments of attention and inhibition. J Am Acad Child Adolesc Psychiatry 56(1):4050. https://doi.org/10.1016/j.jaac.2016.10.006

17. Barkley RA (1997) Behavioral inhibition, sustained attention, and executive functions: constructing a unifying theory of ADHD. Psychol Bull 121(1):65-94

18. Pennington BF, Ozonoff S (1996) Executive functions and developmental psychopathology. J Child Psychol Psychiatry 37(1):51-87

19. Castellanos FX, Tannock R (2002) Neuroscience of attentiondeficit/hyperactivity disorder: the search for endophenotypes. Nat Rev Neurosci 3(8):617-628. https://doi.org/10.1038/nrn89 6

20. Schachar R, Mota VL, Logan GD, Tannock R, Klim P (2000) Confirmation of an inhibitory control deficit in attention-deficit/ hyperactivity disorder. J Abnorm Child Psychol 28(3):227-235. https://doi.org/10.1023/a:1005140103162

21. Willcutt EG, Doyle AE, Nigg JT, Faraone SV, Pennington BFJBp (2005) Validity of the executive function theory of attention-deficit/hyperactivity disorder: a meta-analytic review 57 (11):1336-1346

22. Corbett BA, Constantine LJ, Hendren R, Rocke D, Ozonoff S (2009) Examining executive functioning in children with autism spectrum disorder, attention deficit hyperactivity disorder and typical development. Psychiatry Res 166(2-3):210-222. https:// doi.org/10.1016/j.psychres.2008.02.005

23. Ozonoff S, Cook I, Coon H, Dawson G, Joseph RM, Klin A, McMahon WM, Minshew N, Munson JA, Pennington BF, Rogers SJ, Spence MA, Tager-Flusberg H, Volkmar FR, Wrathall D (2004) Performance on Cambridge neuropsychological test automated battery subtests sensitive to frontal lobe function in people with autistic disorder: evidence from the collaborative programs of excellence in autism network. J Autism Dev Disord 34(2):139-150

24. Damasio AR, Maurer RG (1978) A neurological model for childhood autism. Arch Neurol 35(12):777-786

25. Geurts HM, de Vries M, van den Bergh SFWM (2014) Executive functioning theory and autism. In: Goldstein S, Naglieri JA (eds) Handbook of executive functioning. Springer, New York, pp 121-141. https://doi.org/10.1007/978-1-4614-8106-5_8

26. Russell JE (1997) Autism as an executive disorder. Oxford University Press, Oxford

27. Miyake A, Friedman NP, Emerson MJ, Witzki AH, Howerter A, Wager TD (2000) The unity and diversity of executive functions and their contributions to complex "frontal lobe" tasks: a latent variable analysis. Cogn Psychol 41(1):49-100. https://doi. org/10.1006/cogp.1999.0734

28. Aarnoudse-Moens CSH, Weisglas-Kuperus N, Duivenvoorden HJ, van Goudoever JB, Oosterlaan J (2013) Executive function and IQ predict mathematical and attention problems in very preterm children. PLoS ONE 8(2):e55994. https://doi.org/10.1371/journ al.pone.0055994
29. Mulder H, Pitchford NJ, Marlow N (2010) Processing speed and working memory underlie academic attainment in very preterm children. Arch Dis Child Fetal Neonatal Ed 95(4):F267-272. https ://doi.org/10.1136/adc.2009.167965

30. de Kieviet JF, van Elburg RM, Lafeber HN, Oosterlaan J (2012) Attention problems of very preterm children compared with agematched term controls at school-age. J Pediatr 161(5):824-829. https://doi.org/10.1016/j.jpeds.2012.05.010

31. Craig F, Lamanna AL, Margari F, Matera E, Simone M, Margari L (2015) Overlap between autism spectrum disorders and attention deficit hyperactivity disorder: searching for distinctive/ common clinical features. Autism Res 8(3):328-337. https://doi. org/10.1002/aur.1449

32. Inder TE, Wells SJ, Mogridge NB, Spencer C, Volpe JJ (2003) Defining the nature of the cerebral abnormalities in the premature infant: a qualitative magnetic resonance imaging study. J Pediatr 143(2):171-179. https://doi.org/10.1067/s0022-3476(03)00357-3

33. Miller SP, Ferriero DM, Leonard C, Piecuch R, Glidden DV, Partridge JC, Perez M, Mukherjee P, Vigneron DB, Barkovich AJ (2005) Early brain injury in premature newborns detected with magnetic resonance imaging is associated with adverse early neurodevelopmental outcome. J Pediatr 147(5):609-616. https://doi. org/10.1016/j.jpeds.2005.06.033

34. Cheong JL, Thompson DK, Wang HX, Hunt RW, Anderson PJ, Inder TE, Doyle LW (2009) Abnormal white matter signal on MR imaging is related to abnormal tissue microstructure. AJNR Am J Neuroradiol 30(3):623-628. https://doi.org/10.3174/ajnr.A1399

35. Volpe JJ (2009) Brain injury in premature infants: a complex amalgam of destructive and developmental disturbances. Lancet Neurol 8(1):110-124. https://doi.org/10.1016/s1474-4422(08)70294 $-1$

36. Stuss DT (2011) Functions of the frontal lobes: relation to executive functions. J Int Neuropsychol Soc JINS 17(5):759-765. https ://doi.org/10.1017/s1355617711000695

37. Anderson V, Levin HS, Jacobs R (2002) Executive functions after frontal lobe injury: a developmental perspective. In: Principles of frontal lobe function. Oxford University Press, New York, pp 504-527. https://doi.org/10.1093/acprof:oso/9780195134 971.003.0030

38. Hazy TE, Frank MJ, O'Reilly RC (2007) Towards an executive without a homunculus: computational models of the prefrontal cortex/basal ganglia system. Philos Trans R Soc Lond B Biol Sci 362(1485):1601-1613. https://doi.org/10.1098/rstb.2007.2055

39. Miller EK, Cohen JD (2001) An integrative theory of prefrontal cortex function. Annu Rev Neurosci 24:167-202. https://doi. org/10.1146/annurev.neuro.24.1.167

40. Söderqvist S, Nutley S (2016) Cogmed working memory training. Comput Softw

41. Spencer-Smith M, Klingberg T (2016) Correction: Benefits of a working memory training program for inattention in daily life: a systematic review and meta-analysis. PLoS ONE 11(11):e0167373. https://doi.org/10.1371/journal.pone.0167373

42. Aksayli ND, Sala G, Gobet F (2019) The cognitive and academic benefits of Cogmed: a meta-analysis. Educ Res Rev

43. Anderson PJ, Lee KJ, Roberts G, Spencer-Smith MM, Thompson DK, Seal ML, Nosarti C, Grehan A, Josev EK, Gathercole S, Doyle LW, Pascoe L (2018) Long-term academic functioning following Cogmed working memory training for children born extremely preterm: a randomized controlled trial. J Pediatr 202:92-97.e94. https://doi.org/10.1016/j.jpeds.2018.07.003

44. van Houdt CA, Oosterlaan J, van Wassenaer-Leemhuis AG, van Kaam AH, Aarnoudse-Moens CSH (2019) Executive function deficits in children born preterm or at low birthweight: a meta-analysis. Dev Med Child Neurol. https://doi.org/10.1111/ dmcn. 14213 
45. Mulder H, Pitchford NJ, Hagger MS, Marlow N (2009) Development of executive function and attention in preterm children: a systematic review. Dev Neuropsychol 34(4):393-421. https://doi. org/10.1080/87565640902964524

46. Prins PJ, Brink ET, Dovis S, Ponsioen A, Geurts HM, De Vries M, Van Der Oord S (2013) "Braingame Brian": toward an executive function training program with game elements for children with ADHD and cognitive control problems. Games Health Res Dev Clin Appl 2(1):44-49

47. van der Oord S, Ponsioen AJ, Geurts HM, Ten Brink EL, Prins PJ (2014) A pilot study of the efficacy of a computerized executive functioning remediation training with game elements for children with ADHD in an outpatient setting: outcome on parent- and teacher-rated executive functioning and ADHD behavior. J Atten Disord 18(8):699-712. https://doi.org/10.1177/108705471245316 7

48. Dovis S, Van der Oord S, Wiers RW, Prins PJ (2015) Improving executive functioning in children with ADHD: Training multiple executive functions within the context of a computer game. A randomized double-blind placebo controlled trial. PloS One 10 (4): $\mathrm{e} 0121651$

49. de Vries M, Prins PJ, Schmand BA, Geurts HM (2015) Working memory and cognitive flexibility-training for children with an autism spectrum disorder: a randomized controlled trial. J Child Psychol Psychiatry 56(5):566-576

50. Aarnoudse-Moens CSH, Twilhaar ES, Oosterlaan J, van Veen HG, Prins PJM, van Kaam A, van Wassenaer-Leemhuis AG (2018) Executive function computerized training in very preterm-born children: a pilot study. Games Health J. https://doi. org/10.1089/g4h.2017.0038

51. Jaekel J, Eryigit-Madzwamuse S, Wolke D (2016) Preterm toddlers' inhibitory control abilities predict attention regulation and academic achievement at age 8 years. J Pediatr 169:87-92. e81. https://doi.org/10.1016/j.jpeds.2015.10.029

52. Jaekel J, Wolke D (2014) Preterm birth and dyscalculia. J Pediatr 164(6):1327-1332. https://doi.org/10.1016/j.jpeds .2014.01.069

53. Jackson DC, Lin JJ, Chambers KL, Kessler-Jones A, Jones JE, Hsu DA, Stafstrom CE, Seidenberg M, Hermann BP (2014) Birth weight and cognition in children with epilepsy. Epilepsia 55(6):901-908. https://doi.org/10.1111/epi.12622

54. Jaekel J, Wolke D, Bartmann P (2013) Poor attention rather than hyperactivity/impulsivity predicts academic achievement in very preterm and full-term adolescents. Psychol Med 43(1):183-196. https://doi.org/10.1017/S0033291712001031

55. Verhulst FC, Van der Ende J (2013) Handleiding ASEBA-Vragenlijsten voor leeftijden $6 \mathrm{t} / \mathrm{m} 18$ jaar: CBCL/6-18 YSR en TRF. ASEBA Nederland, Rotterdam

56. Hudziak JJ, Copeland W, Stanger C, Wadsworth M (2004) Screening for DSM-IV externalizing disorders with the child behavior checklist: a receiver-operating characteristic analysis. J Child Psychol Psychiatry 45(7):1299-1307

57. Swanson JM, Schuck S, Porter MM, Carlson C, Hartman CA, Sergeant JA, Clevenger W, Wasdell M, McCleary R, Lakes K, Wigal T (2012) Categorical and dimensional definitions and evaluations of symptoms of ADHD: history of the SNAP and the SWAN rating scales. Int J Educ Psychol Assess 10(1):51-70

58. Huizinga M, Smidts DP (2012) BRIEF Vragenlijst executive functies voor 5- tot 18-jarigen: handleiding. Hogrefe Uitgevers, Amsterdam

59. Sattler JM (1992) Assessment of children: WISC-III and WPPSI-R supplement. Assessment of children: WISC-III and WPPSI-R supplement. Jerome M. Sattler, San Diego

60. Nutley SB, Söderqvist S, Bryde S, Humphreys K, Klingberg $\mathrm{T}$ (2009) Measuring working memory capacity with greater precision in the lower capacity ranges. Dev Neuropsychol 35(1):81-95

61. Aarnoudse-Moens CSH, Duivenvoorden HJ, Weisglas-Kuperus N, Van Goudoever JB, Oosterlaan J (2012) The profile of executive function in very preterm children at 4 to 12 years. Dev Med Child Neurol 54(3):247-253. https://doi.org/10.111 $1 / \mathrm{j} .1469-8749.2011 .04150 . x$

62. Königs M, Weeda WD, van Heurn L, Vermeulen RJ, Goslings JC, Luitse JS, Beelen A, van der Wees M, Kemps RJ, CatsmanBerrevoets CE (2017) Pediatric traumatic brain injury affects multisensory integration. Neuropsychology 31(2):137

63. de Vos T (2010) TempoTest Automatiseren: Handleiding en verantwording. Boom Testuitgevers, Amsterdam

64. Brus BT, Voeten MJM (1973) Eén-Mnuut-Test vorm A en B Verantwoording en Handleiding. Berkenhout Testmateriaal, Nijmegen

65. Van Houdt CA, Aarnoudse-Moens CS, van Wassenaer-Leemhuis AG, Laarman A, Koopman-Esseboom C, van Kaam AH, Oosterlaan J (2019) Effects of executive function training on attentional, behavioral and emotional functioning and selfperceived competence in very preterm children: a randomized controlled trial. Front Psychol 10:2100

66. IBM C (2016) IBM SPSS statistics for windows, version 24.0. IBM Corp., Armonk

67. Ghosh D, Vogt A Outliers: an evaluation of methodologies

68. van Veen S, Aarnoudse-Moens CSH, Oosterlaan J, van Sonderen L, de Haan TR, van Kaam AH, van Wassenaer-Leemhuis AG (2018) Very preterm born children at early school age: healthcare therapies and educational provisions. Early Hum Dev 117:39-43. https://doi.org/10.1016/j.earlhumdev.2017.12.010

69. Central Bureau of Statistics (2020) CBS Statline. https://opend ata.cbs.nl/statline/\#/CBS/nl/dataset/82275NED/table?froms tatweb. Accessed 19 Mar 2020

70. Klingberg T, Fernell E, Olesen PJ, Johnson M, Gustafsson P, Dahlstrom K, Gillberg CG, Forssberg H, Westerberg H (2005) Computerized training of working memory in children with ADHD - a randomized, controlled trial. J Am Acad Child Adolesc Psychiatry 44(2):177-186. https://doi.org/10.1097/00004 583-200502000-00010

71. Dunning DL, Holmes J, Gathercole SE (2013) Does working memory training lead to generalized improvements in children with low working memory? A randomized controlled trial. Dev Sci 16(6):915-925. https://doi.org/10.1111/desc.12068

72. Hovik KT, Saunes BK, Aarlien AK, Egeland J (2013) RCT of working memory training in ADHD: long-term near-transfer effects. PLoS ONE 8(12):e80561. https://doi.org/10.1371/journ al.pone.0080561

73. Melby-Lervåg M, Hulme C (2013) Is working memory training effective? A meta-analytic review. Dev Psychol 49(2):270

74. Shipstead Z, Hicks KL, Engle RW (2012) Cogmed working memory training: Does the evidence support the claims? J Appl Res Memory Cognit 1(3):185-193

75. Murray AL, Thompson DK, Pascoe L, Leemans A, Inder TE, Doyle LW, Anderson JF, Anderson PJ (2016) White matter abnormalities and impaired attention abilities in children born very preterm. NeuroImage 124(Pt A):75-84. https://doi. org/10.1016/j.neuroimage.2015.08.044

76. Taylor HG, Clark CA (2016) Executive function in children born preterm: risk factors and implications for outcome. Semin Perinatol 40(8):520-529. https://doi.org/10.1053/j.sempe ri.2016.09.004

77. de Kieviet JF, Heslenfeld DJ, Pouwels PJ, Lafeber HN, Vermeulen RJ, van Elburg RM, Oosterlaan J (2014) A crucial role for white matter alterations in interference control problems of very preterm children. Pediatr Res 75(6):731-737. https://doi. org/10.1038/pr.2014.31 
78. Krain AL, Castellanos FXJCpr (2006) Brain development and ADHD 26 (4):433-444

79. Lou HC (1996) Etiology and pathogenesis of attention-deficit hyperactivity disorder (ADHD): significance of prematurity and perinatal hypoxic-haemodynamic encephalopathy. Acta Paediatr (Oslo, Norway : 1992) 85 (11):1266-1271

80. Everts R, Murner-Lavanchy I, Schroth G, Steinlin M (2017) Neural change following different memory training approaches in very preterm born children-a pilot study. Dev Neurorehabil 20(1):14-24. https://doi.org/10.3109/17518423.2015.1027010

81. Schaeffer DJ, Krafft CE, Schwarz NF, Chi L, Rodrigue AL, Pierce JE, Allison JD, Yanasak NE, Liu T, Davis CL, McDowell JE (2014) An 8-month exercise intervention alters frontotemporal white matter integrity in overweight children 51(8):728-733. https:doi.org/10.1111/psyp.12227
82. Kelly CE, Thompson DK, Chen J, Josev EK, Pascoe L, Spencer-Smith MM, Adamson C, Nosarti C, Gathercole S, Roberts G, Lee KJ, Doyle LW, Seal ML, Anderson PJ (2020) Working memory training and brain structure and function in extremely preterm or extremely low birth weight children. Hum Brain Mapp 41(3):684-696. https://doi.org/10.1002/hbm.24832

83. Scionti N, Cavallero M, Zogmaister C, Marzocchi GM (2020) Is cognitive training effective for improving executive functions in preschoolers? A systematic review and meta-analysis. Front Psychol 10:2812-2812. https://doi.org/10.3389/fpsyg.2019.02812

84. Green CS, Bavelier DJP, aging (2008) Exercising your brain: a review of human brain plasticity and training-induced learning $23(4): 692$ 